\title{
Evaluating a dimensionally compatible height growth modelling approach
}

\author{
by Yonghe Wang and Bijan Payandeh
}

McDill and Amateis (1992) developed a dimensionally compatible height growth model which may be applied as either a baseage specific or a base-age invariant site index model. Its relative performance was compared with four published site index models on three stem analysis data sets from Ontario and the Northwest Territories of Canada. Results indicated that the modified McDill and Amateis (1992) model performed as well as, if not better than, the other models.

Key words: base-age specific and base-age invariant site index models, nonlinear regression models, sum of squared errors

\section{Introduction}

The ability to measure forest site productivity potential is a critical prerequisite for predicting forest growth and yield (McDill and Amateis 1992). As a result, many height growth pattern or site index models have been developed, including several recent ones by Goelz and Burk (1992) and Payandeh and Wang (1993a). McDill and Amateis (1992) developed and discussed the following height yield model:

$$
H=\frac{\beta_{1}}{1+\left(\frac{\beta_{1}}{H_{0}}-1\right)\left(\frac{t_{0}}{t}\right)^{\beta_{2}}}
$$

where $H$ is stand or tree height $\mathrm{m}, H_{0}$ is initial stand or tree height, $t$ is stand or tree age in year, $t_{0}$ is initial stand or tree age, and $\beta_{1}$ and $\beta_{2}$ are model parameters with $\beta_{1}$ being the upper asymptote.

The model was based on the principle of dimensional compatibility and developed from the following differential equation (McDill and Amkateis 1992):

$$
\frac{d H}{d t}=\beta_{2}\left(\frac{H}{t}\right)\left(\frac{\beta_{1}-H}{\beta_{1}}\right) .
$$

Equation (1) possesses the following properties as a potential site index model (for $\beta_{1}, \beta_{2}>0$ ):

1) $H \rightarrow 0$ as $t \rightarrow 0$,

2) $H \rightarrow \beta_{1}$ or upper asymptote as $t \rightarrow \infty$,

3) $H \rightarrow H_{0}$ as $\mathrm{t} \rightarrow t_{0}$.

All the above mentioned attributes are among the desirable characteristics of a good site index model as described by Goelz and Burk (1992). To apply equation (1) as a base-age specific height (site index) model, it was modified in the following manner:
McDill et Amateis (1992) ont élaboré un modèle de croissance en fonction de la hauteur qui peut être utilisé selon l'âge ou comme un modèle d'indice de la station sans référence à l'âge. La performance relative du modèle a été comparée à quatre modèles publiées d'indice de station à partir de trois ensembles de données d'analyse de tiges provenant de l'Ontario et des Territoires du NordOuest du Canada. Les résultats indiquent que le modèle modifié de McDill et d'Amateis (1992) a donné des résultats satisfaisants, sinon meilleurs que ceux des autres modèles.

Mots clés: modèle d'indice de station en fonction ou sans référence à l'âge, modèles non-linéaires de régression, somme des carrés des erreurs.

$$
H=\frac{\beta_{1} S^{\beta_{2}}}{1+\left(\beta_{1} S^{\beta_{2}-1}-1\right)\left(\frac{t_{i}}{t}\right)^{\beta^{3}}}+\varepsilon
$$

where $S$ is the site index and $t_{i}$ is the index age and $\varepsilon$ is random error with $E(\varepsilon)=0$ and $\operatorname{Var}(\varepsilon)=\sigma^{2}$. Model $(2)$ resembles a simplified version of Yoshida's growth model as discussed by Zeide (1993) where it is written in the form of:

$$
H=\frac{M}{1+N t^{-\beta_{3}}}+\varepsilon=\frac{M t^{\beta_{3}}}{N+t^{\beta_{3}}}+\varepsilon
$$

where

$$
M=\beta_{1} S^{\beta_{2}} \text { and } N=\left(\frac{M}{S}-1\right) t_{i}^{\beta_{3}}
$$

A further modification of (2) will produce its base-age invariant version as:

$$
H_{2}=\frac{\beta_{1} H_{1}^{\beta_{2}}}{1+\left(\beta_{1} H_{1}^{\beta_{2}-1}-1\right)\left(\frac{t_{1}}{t_{2}}\right)^{\beta_{3}}}+\varepsilon
$$

where $H_{1}$ and $H_{2}$ are predictor and predicted heights, and $t_{1}$ and $t_{2}$ are predictor and predicted age, respectively.

$E(H) \rightarrow S$ as $t \rightarrow t_{i}$ and $E\left(H_{2}\right) \rightarrow H_{1}$ as $t_{2} \rightarrow t_{1}$ for models (2) and (3), respectively.

This paper compares the performance of models (2) and (3) with the following base-age specific (4) and (5) and base-age invariant (6) and (7) models:

$$
H=\beta_{1} S^{\beta_{2}}\left(1-e^{-\beta_{3} t}\right)^{\beta_{4} S^{\beta_{5}}}+\varepsilon
$$




$$
\begin{gathered}
H=\beta_{1} S^{\beta_{2}}\left(1-e^{-\beta_{3} t}\right)^{P}+\varepsilon \text { where } \\
p=\frac{1 n\left(\frac{S}{\beta_{1} S^{\beta_{2}}}\right)}{\ln \left(1-e^{-\beta_{3} t_{i}}\right)} \\
H_{2}=H_{1}\left(\frac{1-\exp \left(-\beta_{1}\left(\frac{H_{1}}{t_{1}}\right)^{\beta_{2}} t_{1}^{\beta_{3}} t_{2}\right)}{1-\exp \left(-\beta_{1}\left(\frac{H_{1}}{t_{1}}\right)^{\beta_{2}} t_{1}^{\beta_{3}} t_{1}\right)}\right)^{\beta_{4}}+\varepsilon \\
H_{2}=\beta_{1} H_{1}^{\beta_{2}}\left(1-e^{-\beta_{3} t_{2}}\right)^{P}+\varepsilon \text { where } \\
p=\frac{\ln \left(\frac{\mathrm{H}_{1}}{\beta_{1} H_{1}^{\beta_{2}}}\right)}{\ln \left(1-e^{-\beta_{3} t_{i}}\right)}
\end{gathered}
$$

Models, (4) and (5) were originally proposed by Ek (1971) and by Payandeh and Wang (1993a), respectively. Models (6) and (7) were developed by Goelz and Burk (1992) and Payandeh and Wang (1993b), respectively.

\section{Materials and Methods}

Three stem analysis data sets were used to evaluate the models: (1) an aspen (Populus tremuloides Michx.) data set from north central Ontario consisting of 144 trees, described by Deschamps (1991); (2) a white spruce (Picea glauca (Moench) Voss) data set from the MacKenzie District of the Northwest Territories with 210 trees, described by Newnham (1988) and Alemdag (1988); and (3) a black spruce (Picea mariana (Mill.) B.S.P.) data set. In the black spruce data, 230 trees were selected from sample plots located in north central Ontario established during the last decade for various studies. Trees were cut at $15 \mathrm{~cm}$ (stump height), $75 \mathrm{~cm}, 130 \mathrm{~cm}, 2 \mathrm{~m}$, at $1 \mathrm{~m}$ intervals from 2 to $13 \mathrm{~m}$, and at $50 \mathrm{~cm}$ intervals thereafter. Stem analysis was completed using the TRIM system (Fayle et al. 1983; MacIvor et al. 1985). Height, age at breast height and DBH were derived via the TRIM software from age one to the total age by one year intervals. Heights at five-year intervals (e.g. heights at ages $5,10,15, \ldots)$ and index age 40 for aspen and 50 for the spruces were used in the analysis.

Two different data structures were necessary to fit the baseage specific and base-age invariant models (Payandeh and Wang 1993b). Equations (2), (4), and (5) were fitted using the original data sets containing age, height and site index for each observation and each tree. Goelz and Burk (1992) used all height and age measurements to fit a base-age invariant site index model for predicting all other heights for a tree. For example, a tree with 10 measurements would provide 90 observations, each height predicted in turn by nine heights at other ages. This method generates a large number of observations which may not be necessary. Here, a structure with only two adjacent observations was used. For example, height at age $t$ is predicted by heights at ages $t \pm 5$ years. To fit equations (3), (6) and (7), the data structure consisted of $H_{t} H_{t-1}, t$ and $t-1$ for each observation on each tree.

The equations were evaluated using the root mean squared error (RMSE), the mean absolute deviation (MAD), and the average bias (MBIAS). These statistics are defined as follows:

$$
R M S E=\sqrt{\frac{\sum_{j=1}^{K} \sum_{i=1}^{N_{i}}\left(H_{i j}-\hat{H}_{i j}\right)}{\sum_{j=1}^{K} N_{j}}}
$$

$$
M A D=\frac{\sum_{j=1}^{K} \sum_{i=1}^{N_{i}}\left|H_{i j}-\hat{H}_{i j}\right|}{\sum_{j=1}^{K} N_{j}}
$$

$$
M B I A S=\frac{\sum_{j=1}^{K} \sum_{i=1}^{N_{i}}\left(H_{i j}-\hat{H}_{i j}\right)}{\sum_{j=1}^{K} N_{j}}
$$

where $H_{i j}$ is the observed height for the $j$ th tree at the $i$ th section height in a data set, $\hat{H}_{i j}$ is the estimated height via a fitted model for the $j$ th tree at the $i$ th section height in the data set, $N_{j}$ is the number of sections for the $j$ th tree, and $K$ is the number of trees in the data set

Index ages 40 or 50 and the corresponding heights as $S$ were used for the base-age specific equations (2), (4) and (5). Ages 40 or 50 and the corresponding heights were treated as $t_{1}$ and $H_{1}$ when RMSE, MAD, and MBIAS were calculated for the fitted base-age invariant equations (3), (6), and (7).

\section{Results and Discussion}

RMSE, MAD, and MBIAS for the six equations are given (Table 1). Site index curves generated from equations (2), (4), and (5) fitted to the aspen, white spruce and black spruce data sets, respectively are shown (Fig. 1). Site index curves were generated (Fig. 2) from equations (3), (6), and (7) fitted to the same data sets.

The base-age specific models produced more accurate results than the base-age invariant ones, as evidenced by any of the three statistics RMSE, MAD and/or MBIAS (Table 1). Evaluated by the MBIAS, equations (2) and (3) do not perform the best; however, judged by RMSE or MAD, they are more accurate than the other equations in most cases.

Equation (4) is an excellent base-age specific site index model, but it does not satisfy the site index definition (i.e. $H \neq S$ as $t$ $\rightarrow t_{i}$ ). Equation (5) was developed to overcome this shortcoming. Equation (2) is the simplest model, having only three parameters as compared with the five parameters of equation (4). In addition to performing very well, equation (2) intrinsically has the properties of $H \rightarrow 0$ as $t \rightarrow 0$ and $H \rightarrow S$ as $t \rightarrow t_{i}$. The above reasoning applies to equation (3), a base-age invariant version of equation (2), as well. 
Table 1. Number of observations (N), estimated parameters, $\mathrm{R}^{2}$, RMSE, MAD, and MBIAS for equations (2) - (7) fitted to the aspen, black spruce and white spruce three stem analysis data sets

\begin{tabular}{|c|c|c|c|c|c|c|c|c|c|c|c|}
\hline \multirow[b]{2}{*}{ Species } & \multirow[b]{2}{*}{ Eq. } & \multirow[b]{2}{*}{$N$} & \multicolumn{5}{|c|}{ Parameters } & \multirow[b]{2}{*}{$R^{2}$} & \multirow[b]{2}{*}{ RMSE } & \multirow[b]{2}{*}{ MAD } & \multirow[b]{2}{*}{ MBIAS } \\
\hline & & & $b_{1}$ & $b_{2}$ & $b_{3}$ & $b_{4}$ & $b_{5}$ & & & & \\
\hline \multirow{6}{*}{ Aspen } & (2) & 2062 & 10.6634 & 0.4336 & 1.2993 & \multirow{3}{*}{2.7724} & \multirow{3}{*}{-0.2957} & .97 & 1.17 & 0.86 & .008 \\
\hline & (4) & 2062 & 3.7048 & 0.7379 & 0.0242 & & & .97 & 1.17 & 0.87 & -.003 \\
\hline & (5) & 2062 & 3.4015 & 0.7647 & 0.0251 & & & .97 & 1.19 & 0.88 & .003 \\
\hline & (3) & 3836 & 6.5378 & 0.5092 & 1.7093 & \multirow{3}{*}{1.8842} & & .99 & 1.40 & 1.03 & 0.55 \\
\hline & (6) & 3836 & 0.4233 & 0.6350 & -0.4527 & & & .99 & 1.57 & 1.13 & 0.70 \\
\hline & (7) & 3836 & 2032.69 & -0.9908 & 0.0013 & & & .99 & 1.79 & 1.28 & -0.85 \\
\hline \multirow{6}{*}{ White spruce } & (2) & 2340 & 70.2442 & -0.2457 & 1.4114 & \multirow{3}{*}{7.6492} & \multirow{3}{*}{-0.6897} & .93 & 1.96 & 1.30 & 0.04 \\
\hline & (4) & 2340 & 14.3005 & 0.3002 & 0.0146 & & & .93 & 1.97 & 1.34 & 0.02 \\
\hline & (5) & 2340 & 14.6485 & 0.2808 & 0.0158 & & & .93 & 1.97 & 1.33 & -0.05 \\
\hline & (3) & 4260 & 10.4387 & 0.3872 & 1.5688 & \multirow{3}{*}{1.3145} & & .99 & 2.35 & 1.46 & 0.79 \\
\hline & (6) & 4260 & 0.0659 & 1.1770 & 0.0582 & & & .99 & 2.12 & 1.33 & 0.44 \\
\hline & (7) & 4260 & 1158.40 & -0.8309 & 0.0013 & & & .99 & 2.35 & 1.58 & -0.84 \\
\hline \multirow{6}{*}{ Black spruce } & (2) & 4160 & 53.2945 & -0.1005 & 0.9727 & \multirow{3}{*}{1.8640} & \multirow{3}{*}{-0.3111} & .97 & 0.82 & 0.57 & 0.08 \\
\hline & (4) & 4160 & 5.9522 & 0.6298 & 0.0092 & & & .97 & 0.81 & 0.58 & 0.03 \\
\hline & (5) & 4160 & 6.1141 & 0.6198 & 0.0095 & & & .97 & 0.84 & 0.59 & 0.04 \\
\hline & (3) & 7264 & 7.1679 & 2.0424 & -0.6974 & \multirow{3}{*}{0.7018} & & .99 & 1.03 & 0.63 & -0.13 \\
\hline & (6) & 7264 & 6.0523 & -3.7866 & -4.5689 & & & .99 & 1.05 & 0.63 & -0.15 \\
\hline & (7) & 7264 & 7.3264 & 0.4145 & 0.0208 & & & .99 & 1.10 & 0.83 & 0.23 \\
\hline
\end{tabular}

Note: $b_{i}$ is the estimated value of paramater $\beta_{i}$.
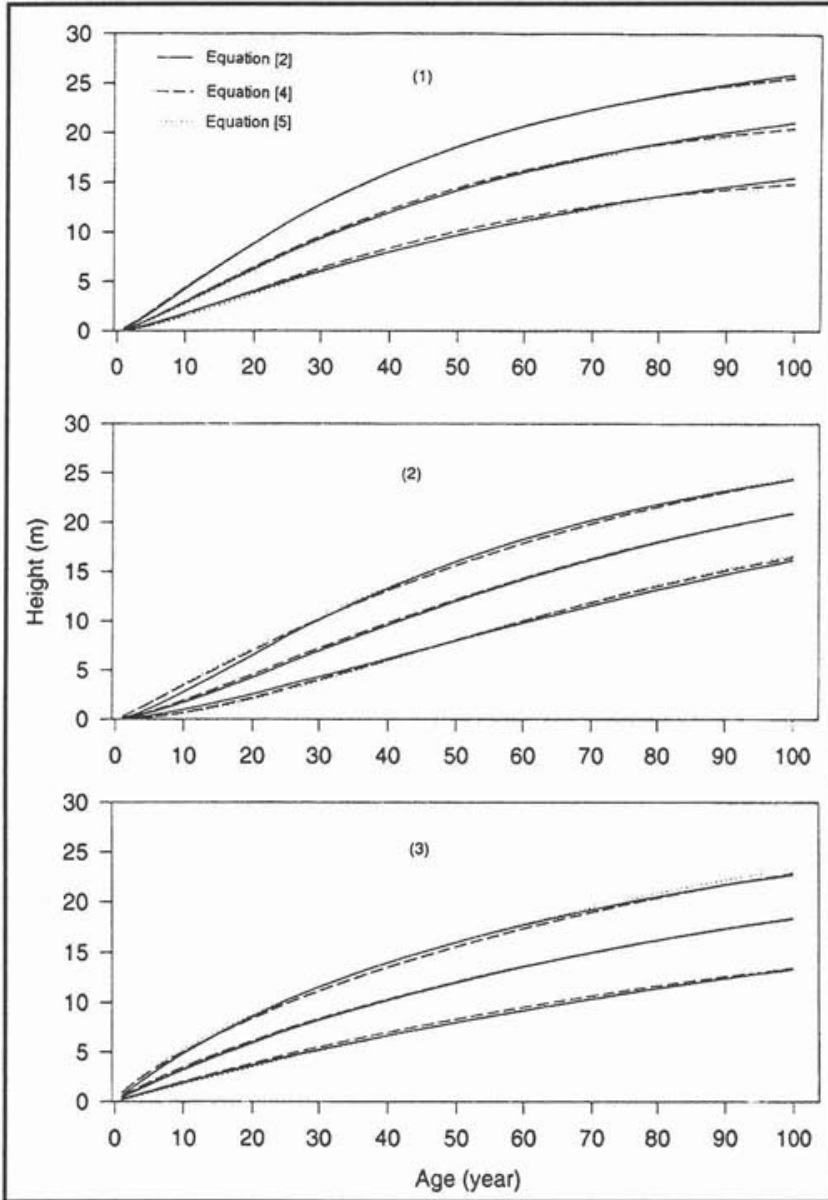

Fig. 1. Aspen [ (1) index age $=40$ years], white spruce $[(2)$ index age $=50$ years $]$ and black spruce $[(3)$ index age $=50$ years $]$ site index curves based on equations $(2)(-),(4)(---)$, and $(5)(\cdots)$, (indices $=8,12$ and $16 \mathrm{~m})$.
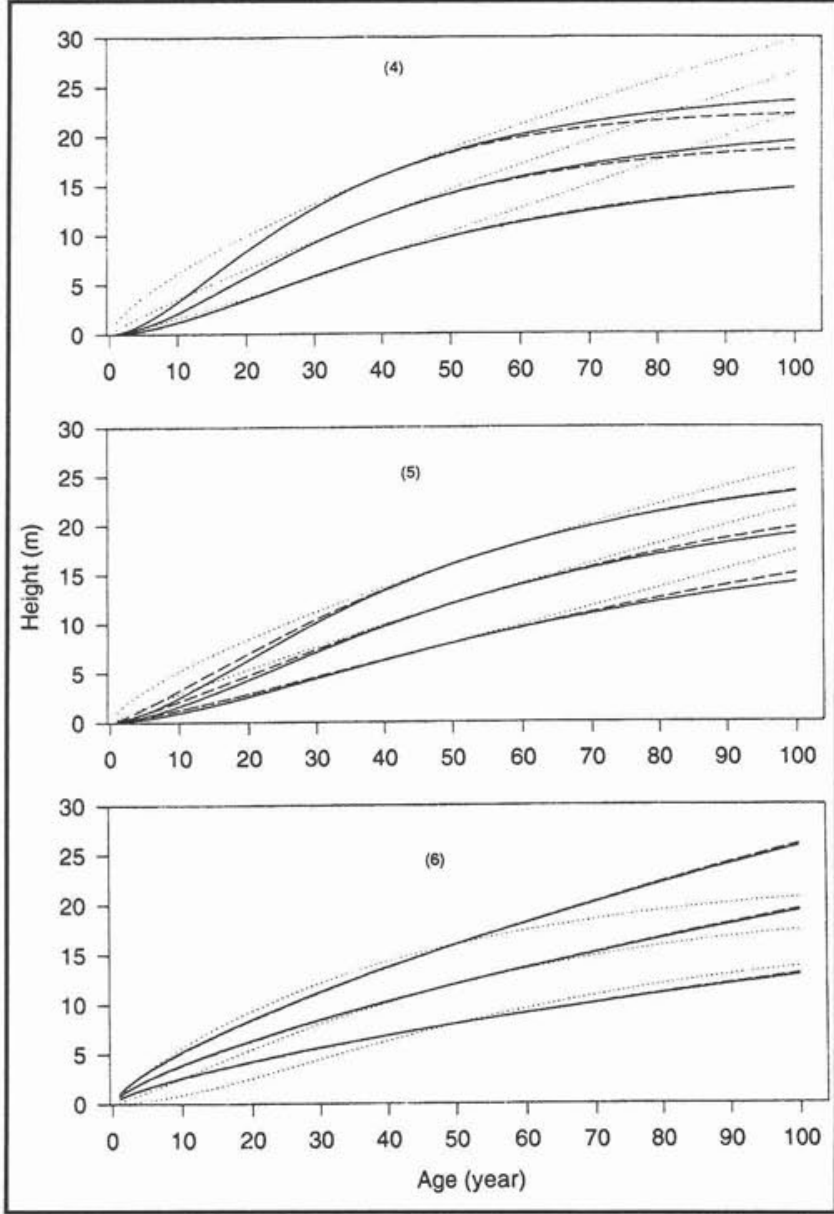

Fig. 2. Aspen [(4) $t_{1}=40$ years], white spruce $\left[(5) t_{1}=50\right.$ years $]$ and black spruce $\left[(6) t_{1}=50\right.$ years] site index curves based on equations (3) $(-),(6)(---)$, and (7) $(\cdots),\left(H_{1}=8,12\right.$ and $\left.16 \mathrm{~m}\right)$. 


\section{Conclusion}

A modification of McDill and Amateis (1992) height growth model can provide a useful base-age specific as well as a base-age invariant site index model. More extensive evaluation of these models on larger and different data sets is recommended to verify the conclusions reached in this study.

\section{Acknowledgement}

We thank the Canadian Forest Service for providing funding for this study. Appreciations are due Monty Newnham, Petawawa National Forestry Institute, Chalk River, Ontario, and Bill Towill and Mark Roddick of Northwest Region Science and Technology Section, Ontario Ministry of Natural Resources, Thunder Bay, Ontario, for providing the data.

\section{References}

Alemdag, I.S. 1988. Site index equations for white spruce in the Northwest Territories, Canada. For. Ecol. Manage. 23: 61-71.

Deschamps, K.C. 1991. Height growth and site index of trembling aspen in north central Ontario. M.Sc.F. thesis. Faculty of Forestry, Lakehead Univ., Thunder Bay, ON.
Ek, A.R. 1971. A formula for white spruce site index curves. Univ. Wisc. For. Res. Note No. 161. 2p.

Fayle, D.C.F., D.C. MacIvor and C.V. Bantly. 1983. Computer graphing of annual ring widths during measurements. Forest Chron. 59: 291-293.

Goelz, J.C.G. and T.E. Burk. 1992. Development of a well-behaved site index equation: jack pine in north central Ontario. Can. J. For. Res. 22: 776-784.

MacIvor, D.C., F. Raymond and H. Dallans. 1985. TRIM sampling design manual. Forest Resources Group, Ontario Ministry of Natural Resources, Queen's Park. Toronto, ON. 200+p.

McDill, M.E. and R.L. Amateis. 1992. Measuring forest site quality using parameter estimates for a dimensionally compatible growth function. For. Sci. 38: 409-429.

Newnham, R.M. 1988. A modification of the Ek-payandeh nonlinear regression model for site index curves. Can. J. For. Res. 18: 115-120.

Payandeh, B. and Y. Wang. 1993a. A site index model remodified. Can. J. For. Res. 24: 197-198.

Payandeh, B. and Y. Wang. 1993b. Relative accuracy of a new baseage invariant site index model. For. Sci. 40: 341-348.

Zeide, B. 1993. Analysis of growth equations. For. Sci. 39: 594-616. 